\title{
Effects of an Acute Increase in Plasma Triglyceride Levels on Glucose Metabolism in Man
}

\author{
P.M. Piatti, L.D. Monti, L. Baruffaldi, F. Magni, R. Paroni, I. Fermo, S. Costa, G. Santambrogio, R. Nasser, M. Marchi, \\ M. Galli-Kienle, A.E. Pontiroli, and G. Pozza
}

The aim of the study was to evaluate the effects of an acute increase in triglyceride levels induced by Intralipid (Kabivitrum, Stockholm, Sweden) infusion on forearm glucose uptake, glucose oxidative metabolism, and hepatic glucose production independent of circulating free fatty acid (FFA) levels in man. Six normal subjects underwent three different tests in random order. Each test consisted of a control period of 120 minutes followed by a euglycemic, hyperinsulinemic clamp lasting 120 minutes. In test 1, a high-dose intravenous Intralipid infusion was performed to increase triglyceride and FFA levels. In test 2, heparin $(30 \mathrm{U} / \mathrm{min}$ ) plus low-dose Intralipid infusions were performed to maintain triglyceride at normal levels and increase only FFA levels. Test 3 was performed as a control study. During the 120-minute control period, forearm glucose uptake and hepatic glucose production were not affected by increasing only FFA levels (test 2) or FFA and triglyceride levels (test 1) as hepatic glucose production were not affected by study during tests 1 and 2 , without a further significant decrease during simultaneously increased FFA and triglyceride levels. study during tests 1 and 2 , with was similar in tests 1 and 2 , at values significantly greater than in test 3 . During the euglycemic Concomitantly, lipid oxidation was similar in tests 1 and 2, at values significantly greater than in test 3 . During the euglycemic clamp, forearm glucose uptake and glucose de levels during test 1 caused a significant $30 \%$ to $40 \%$ decrease of both parameters the control period, the increase of triglyceride levels during test 1 caused a significant $30 \%$ to $40 \%$ decrease of both 1 as compared with the control period but significantly decreased during tests 2 and 3 . Hepatic glucose production was less inhibited during test 1 than during tests 2 and 3 , and less so during test 2 than test 3 . In conclusion, at least under these particular conditions, acute hypertriglyceridemia induced by Intralipid infusion seems to decrease forearm glucose uptake, glucose oxidation, and insulin-induced suppressibility of hepatic glucose production. Taking our results together, it seems that the triglyceride effect on carbohydrate metabolism occurs via triglyceride hydrolysis using the intracellular pathways of FFA without interference with the circulating FFA pool.

Copyright $\odot 1995$ by W.B. Saunders Company

$\mathbf{I}^{\mathrm{s}}$ NSULIN RESISTANCE and hypertriglyceridemia are strictly interrelated to such a degree that several investigators ${ }^{1,2}$ have suggested the existence of a syndrome (syndrome $\mathrm{X}$, or insulin-resistance syndrome) characterized by hyperinsulinemia, hypertriglyceridemia, hypertension, coronary artery disease, insulin resistance, and impaired glucose tolerance. Although there is much evidence suggesting that hypertriglyceridemia is a consequence of insulin resistance, little is known about the effects of triglycerides on insulin sensitivity. Previous studies have shown that in normal subjects, impaired-glucose tolerance subjects, and noninsulin-dependent diabetes mellitus (NIDDM) subjects, there is an inverse relationship between triglyceride levels and insulin sensitivity. ${ }^{3,4}$ Epidemiologic data indicated that insulin resistance precedes the development of hypertriglyceridemia. In addition, insulin stimulates triglyceride verylow-density lipoprotein synthesis, ${ }^{3}$ and long-term therapy with gemfibrozil improves glucose tolerance and insulin levels during oral glucose tolerance tests in subjects with severe hypertriglyceridemia. ${ }^{5}$ Recently, Yki-Jarvinen and Taskinen ${ }^{6}$ and Widen et $\mathrm{al}^{7}$ have shown that hypertriglyceridemic NIDDM patients are more insulin-resistant than matched nonhypertriglyceridemic patients. On the other hand, a reduction in triglyceride levels via gemfibrozil or bezafibrate therapy did not improve insulin sensitivity in mildly hypertriglyceridemic NIDDM patients or in hypertriglyceridemic patients. 8,9

The aim of this study was to evaluate the effects of acute hypertriglyceridemia on forearm glucose uptake, glucose oxidation, and hepatic glucose production in man. To the best of our knowledge, the only way to produce an acute increase in triglyceride levels is to use an Intralipid infu- sion. ${ }^{10,11}$ However, since this also increases free fatty acid (FFA) levels, ${ }^{12,13}$ it could become impossible to discriminate between the effects of FFA and those of triglycerides on glucose metabolism. On the other hand, it is also possible to increase FFA levels without changing triglyceride levels by using heparin infusion with or without lowdose Intralipid (Kabivitrum, Stockholm, Sweden). ${ }^{14,15}$ Therefore, we designed a study in which both FFA and triglyceride levels or only FFA levels were increased. Thus, by comparing results, we were able to calculate the effects of triglycerides on glucose metabolism.

\section{SUBJECTS AND METHODS}

The protocol of the study was approved by the local Ethics Committee, and written informed consent was obtained from all subjects. Six normal men (mean \pm SE: age, $27.7 \pm 0.9$ years; body mass index, $24.5 \pm 0.7 \mathrm{~kg} / \mathrm{m}^{2}$; weight, $80.1 \pm 4.5 \mathrm{~kg}$; fat-free mass $[\mathrm{FFM}], 60.8 \pm 2.6 \mathrm{~kg}$; and fat mass, $19.2 \pm 2.7 \mathrm{~kg}$ ) were admitted to the metabolic unit in the morning after an overnight fast. Subjects were nonsmokers and were taking no medication. Each subject underwent three different tests in random order, with at least a 15-day interval between two consecutive tests. Test 1 was designed to increase triglyceride and FFA levels, test 2 to increase only FFA levels, and test 3 as a control study. Each test consisted of a control

From the Istituto Scientifico H. San Raffaele, Cattedra di Clinica Medica, Laboratorio di Spettrometria di Massa e HPLC, and Dipartimento di Biochimica Clinica, University of Milan, Milan, Italy.

Submitted April 13, 1994; accepted October 22, 1994.

Address reprint requests to P.M. Piatti, MD, Istituto Scientifico $H$. San Raffaele, Via Olgettina 60, 20132 Milano, Italy.

Copyright $\odot 1995$ by W.B. Saunders Company

0026-0495/95/4407-0009\$03.00/0 
period of 120 minutes followed by a euglycemic, hyperinsulinemic clamp lasting 120 minutes, combined with Intralipid 20\% (2.5 $\mathrm{mL} / \mathrm{min}$ ) intravenous infusion (test 1$)$, heparin $(30 \mathrm{U} / \mathrm{min})$ plus Intralipid $20 \%(0.5 \mathrm{~mL} / \mathrm{min})$ infusions (test 2$)$, or saline infusion (test 3). Test 1 and test 2 were preceded by a $250-\mathrm{U}$ heparin intravenous bolus (Fig 1). Five pilot studies were performed to determine optimal rates of Intralipid and heparin infusions to achieve target triglyceride and FFA levels (data not shown). The euglycemic, hyperinsulinemic clamp consisted of a continuous insulin $(25 \mathrm{mU} / \mathrm{kg} / \mathrm{h})$ infusion test lasting 120 minutes, with blood glucose levels maintained at basal values via a variable glucose $(20 \%)$ infusion. ${ }^{16}$ Changes in glucose infusion were made according to measurements obtained every 5 minutes from a glucose analyzer (Yellow Springs Instrument, Yellow Springs, Fullerton, $\mathrm{OH})$. On the morning of each test, a 20 -gauge plastic cannula (Abbocath T; Abbot, Ireland, Sligo, Republic of Ireland) was inserted in a dorsal vein of one hand in a retrograde position, and the hand was placed in a Plexiglas box and maintained at $55^{\circ} \mathrm{C}$ for intermittent sampling of arterialized blood. An 18-gauge plastic cannula was inserted into a large antecubital vein of the same arm for infusions, and another 18-gauge plastic cannula was inserted in a retrograde position into a large, deep antecubital vein of the contralateral arm for intermittent sampling of deep venous forearm blood.

Blood flow of the proximal forearm was determined at each blood sampling using venous-occlusion plethysmography (control period: $105,110,115$, and 120 minutes; clamp period: $225,230,235$, and 240 minutes), with a collecting pressure of $60 \mathrm{~mm} \mathrm{Hg}$ and a wrist-occlusion pressure of $220 \mathrm{~mm} \mathrm{Hg}$ inflated simultaneously. Each measurement is the mean of a minimum of four occlusions, with a range of coefficient of variation (CV) values from $4.39 \%$ to $7.06 \%$. The CV of the eight blood-flow measurements performed during the final 30 minutes of the control and clamp periods of each study was calculated as an index of intrastudy variability. During the control period, mean CVs were $3.8 \pm 0.6 \%, 6.6 \pm 1.4 \%$, and $4.8 \pm 1.3 \%$, respectively, during tests 1,2 , and 3 ; during the clamp period, mean CVs were $5.9 \pm 1.6 \%, 4.7 \pm 0.8 \%$, and $6.0 \pm$ $1.3 \%$, respectively, during tests 1,2 , and 3 . Changes in forearm volume were measured using a temperature-compensated mercury, rubber strain gauge placed distally to the tip of the cannula. ${ }^{17}$ The wrist cuff was inflated to $220 \mathrm{~mm} \mathrm{Hg} 3$ minutes before and during venous sampling, to exclude hand blood flow from forearm measurement. Calibration of the apparatus was made immediately after venous sampling. Blood flow was determined as milliliters per minute per $100 \mathrm{~mL}$ forearm volume tissue. Forearm circumference

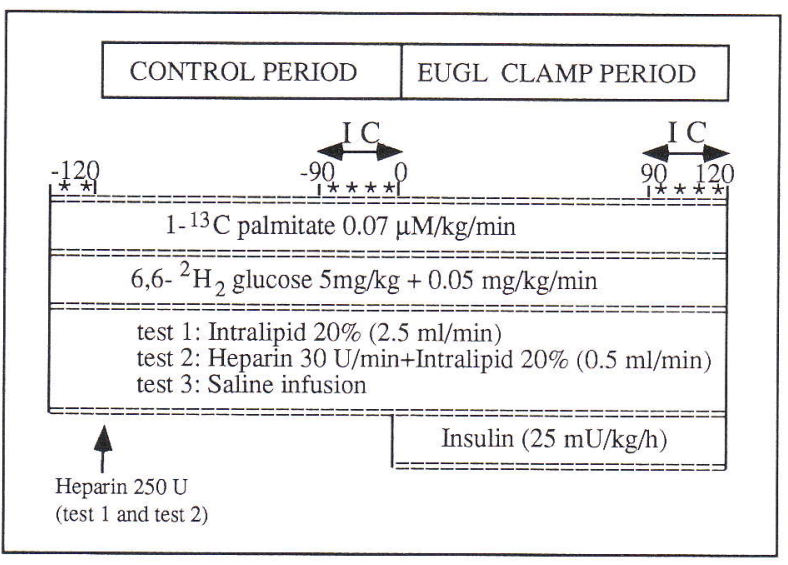

Fig 1. Study design. *Arterialized venous samples. IC, indirect calorimetry; EUGL, euglycemic. was measured at the proximal and distal borders of the plethysmography cuff, and the contained volume was calculated using the equation of a truncated cone. All measurements of total blood flow were less than $4.0 \mathrm{~mL} / 100 \mathrm{~mL}$ forearm $/ \mathrm{min}$, and we have therefore used the following equation for estimation of forearm muscle blood flow (FMBF) in milliliters per $100 \mathrm{~mL}$ forearm per minute ${ }^{18}$ : $\mathrm{FMBF}=0.47$ (total forearm blood flow $)+0.83$. Forearm uptake or release of glucose and metabolites (lactate, pyruvate, $\beta-\mathrm{OH}$ butyrate, alanine, and citrate) was calculated in the following manner: (arterialized venous blood concentration - deep venous blood concentration) $\times$ FMBF. Plasma glucose values were converted to whole-blood values by multiplying plasma values by [ $1-(0.37 \times$ hematocrit $)]$. In each study, arterialized and deep venous sampling were obtained simultaneously for glucose, metabolites, FFA, and triglycerides at $105,110,115$, and 120 minutes before the clamp and $225,230,235$, and 240 minutes during the clamp.

FFM and fat mass were calculated using the equation reported by Heymsfield et al, ${ }^{19}$ which takes into account midarm circumference and abdominal and triceps skinfold thickness.

The total glucose disposal rate was evaluated isotopically using a primed $(5 \mathrm{mg} / \mathrm{kg})$-continuous $(0.05 \mathrm{mg} / \mathrm{kg} / \mathrm{min})$ infusion of $[6,6-$ ${ }^{2} \mathrm{H}_{2}$ ] glucose. During the clamp period, blood glucose was kept constant by means of a variable infusion of $20 \%$ dextrose. A fixed amount of dideuterated glucose was also added to the glucose bag ( $1.4 \%$ of cold glucose) to keep isotopic enrichment constant. ${ }^{20}$ The rate of appearance of unlabeled glucose was calculated using Steele's model, ${ }^{21}$ taking into account the nonnegligible mass stable isotope in the way indicated by Cobelli et al. ${ }^{22}$ Rates of hepatic glucose production were calculated by subtracting the rate of exogenously infused glucose ( $\mathrm{M}$ value) from the isotopically measured rate of disappearance of the tracer.

To address better the point of whether triglyceride effects are independent from the circulating FFA pool, we evaluate palmitate turnover using a continuous infusion of $\left[1-{ }^{13} \mathrm{C}\right]$ palmitate $(0.06$ $\mu \mathrm{mol} / \mathrm{kg} / \mathrm{min}$ ) throughout the three test periods. In fact, palmitate is the second most abundant FFA in plasma, and its fractional turnover rate is representative of the total FFA pool.

During the last 30 minutes (control and euglycemic clamp periods), rates of glucose $\left(\mathrm{G}_{\mathrm{OX}}\right)$ and lipid ( $\left.\mathrm{L}_{\mathrm{OX}}\right)$ oxidation were calculated at 1-minute intervals using indirect calorimetry (Deltatrac; Datex, Helsinki, Finland), which measured oxygen uptake $\left(\mathrm{V}_{\mathrm{CO}_{2}}\right)$ and carbon dioxide production $\left(\dot{\mathrm{V}}_{\mathrm{CO}_{2}}\right)$. The following equations were used ${ }^{23}: \mathrm{G}_{\mathrm{OX}}=4.55 \dot{\mathrm{V}}_{\mathrm{CO}_{2}}-3.21 \mathrm{~V}_{2}-2.87 \mathrm{~N}$, and $\mathrm{L}_{\mathrm{OX}}=1.67 \dot{\mathrm{V}} \mathrm{CO}_{2}-1.67 \mathrm{VCO}_{2}-1.92 \mathrm{~N}$. Protein oxidation was calculated by multiplying urinary $\mathrm{N}$ excretion by $6.25^{24}$ and normalized by urea clearance..$^{24}$ The urinary nitrogen excretion rate was calculated by collecting urine samples throughout the test.

\section{Assays}

All samples were assayed for metabolites and insulin in a single assay. In particular, serum insulin (intraassay CV $3.0 \%$, interassay CV $5.0 \%$ ) was measured by radioimmunoassay using commercial kits.

Samples for metabolites were collected into weighted tubes containing chilled $0.5-\mathrm{mol} / \mathrm{L}$ perchloric acid. Blood $\beta$-OH-butyrate (intraassay CV $3.0 \%$, interassay CV $10.0 \%$ ), glycerol (intraassay CV $3.0 \%$, interassay CV $3.0 \%$ ), lactate (intraassay CV $4.0 \%$, interassay CV $7.5 \%$ ), pyruvate (intraassay CV $8.0 \%$, interassay CV $9.5 \%$ ), and alanine (intraassay CV 6.0\%, interassay CV 10.0\%) were assayed using automated enzymatic spectrofluorimetric methods adapted to a Cobas Fara II analyzer (Hoffman-La Roche, Basel, Switzerland ${ }^{25}$ ), whereas plasma FFA (intraassay CV 3.0\%, interassay CV $3.0 \%$ ) and serum triglyceride levels were measured using an automated enzymatic spectrophotometric technique 
adapted to the Cobas Fara II. Citrate levels were assayed using a commercial kit (Boehringer-Mannheim, Milan, Italy) with the following changes to adapt the method to a Cobas Fara II. The solution was diluted 1:150 with distilled water; the final concentration of NADH was $0.04 \mathrm{mg} / \mathrm{mL}$, malate dehydrogenase 0.90 $\mathrm{U} / \mathrm{mL}$, and lactate dehydrogenase $1.86 \mathrm{U} / \mathrm{mL}$. For each sample, $0.04 \mathrm{U}$ citrate lyase was added to start the reaction. The following standard concentrations were used: $0,32.5,65.06,130.1$, and 260.2 $\mu \mathrm{mol} / \mathrm{L}$. Standards and samples were prepared by adding $1 \mathrm{~mL}$ perchloric acid $3 \%$ to $1 \mathrm{~mL}$ of samples and neutralized by $0.5 \mathrm{~mL}$ $0.3-\mathrm{mol} / \mathrm{L} \mathrm{K}_{2} \mathrm{CO}_{3}$. The intraassay $\mathrm{CV}$ was $3.0 \%$, and the interassay $\mathrm{CV}$ was $6.0 \%$. Alanine plasma levels were assayed with an $o$-phthaldialdehyde precolumn derivatization reaction followed by high-performance liquid chromatography analysis on an RP-C18 column and fluorometric detection. ${ }^{26}$

Isotopic enrichment of $\left[6,6-{ }^{2} \mathrm{H}_{2}\right]$ glucose was measured using the gas chromatographic-mass spectrometric method previously reported. ${ }^{27}$ Weighed amounts of $\left[1-{ }^{13} \mathrm{C}\right]$ palmitic acid (99 atom percent excess [APE]) were bound to fatty acid-free human albumin (ORHA, Behring, Germany), and the solution was then filtered through a 0.8 - and a $0.22-\mu \mathrm{m}$ sterile filter before infusion to human subjects. Palmitic acid levels and enrichment were determined after plasma extraction, using heptadecanoic acid as inter- nal standard and methylation of the crude extracts with diazomethane, and the samples were then analyzed by gas chromatographymass spectrometry. Details of the method are reported by Magni et al. ${ }^{28}$

\section{Statistical Analysis}

Each variable is expressed as the mean \pm SE at each time interval. Comparisons between experiments were made by means of two-way ANOVA followed by Student's $t$ test for paired data. $P$ values less than .05 were considered statistically significant.

\section{RESULTS}

\section{Control Period}

Arterialized levels. During test 1, triglyceride and FFA levels achieved a plateau at $3.9 \pm 0.5$ and $1.7 \pm 0.3 \mathrm{mmol} / \mathrm{L}$, respectively, whereas during test 2 , triglyceride and FFA levels were $0.8 \pm 0.2$ and $1.8 \pm 0.2$, respectively $(P<.05$ for triglyceride levels, NS for FFA levels). In test 3 , triglycerides and FFA remained at basal levels (Fig 2).

$\beta$-OH-butyrate and glycerol levels were significantly higher in test 1 than in tests 2 and 3, and higher in test 2
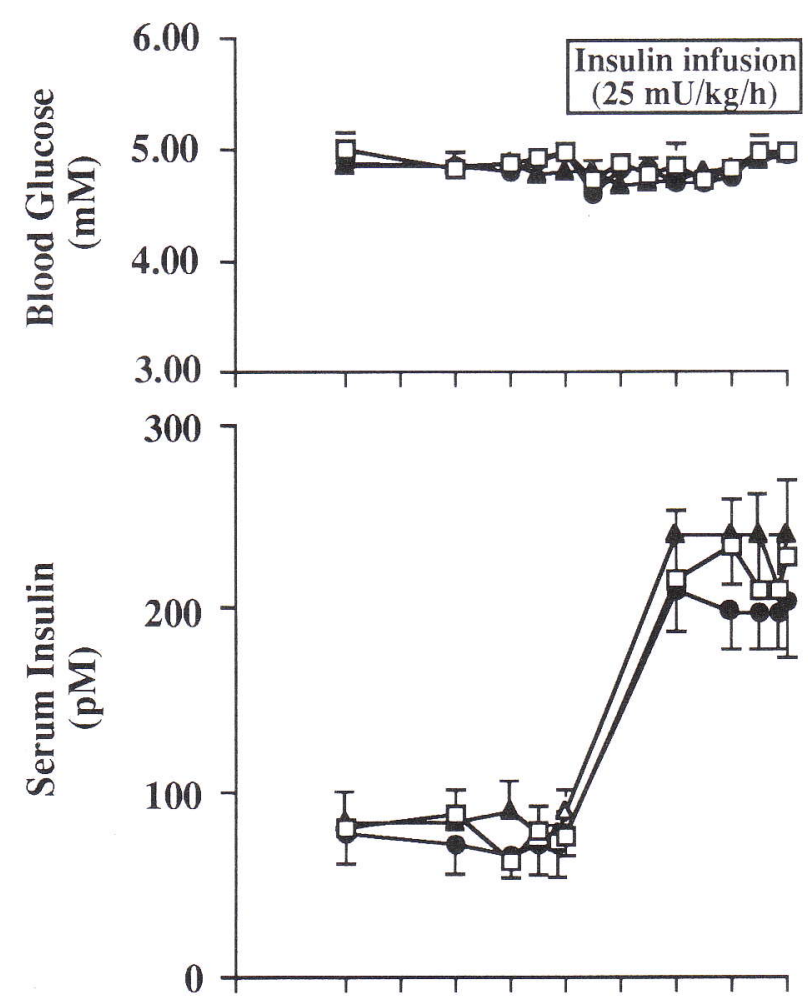
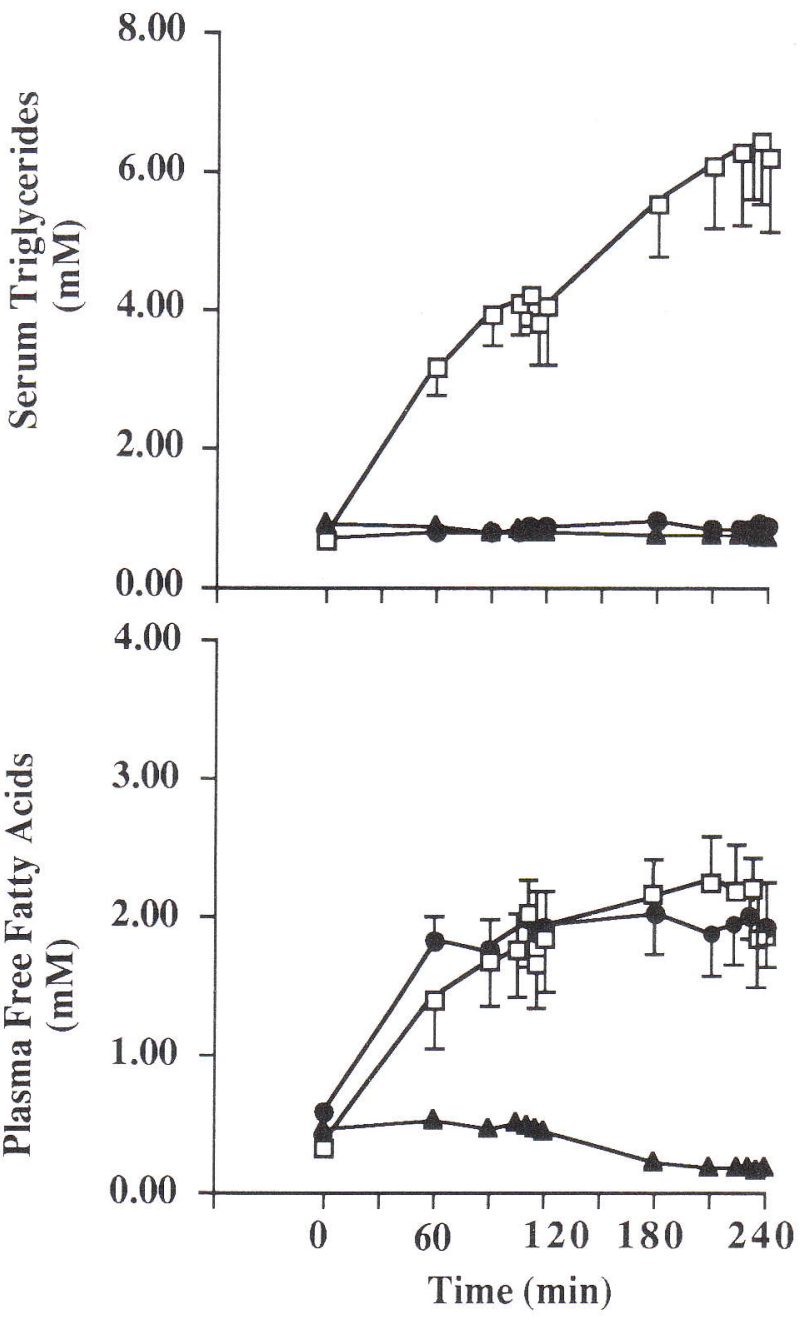

Fig 2. Blood glucose, serum insulin, serum triglyceride, and plasma FFA levels during control and clamp periods (mean \pm SE). ( $\square$ ) Test 1 , increased FFA and triglyceride levels; ( $)$ test 2, increased FFA levels; ( $\mathbf{\Delta}$ ) test 3 , control study. 
than in test 3 (Table 1). The different Intralipid and heparin infusions used to achieve target triglyceride and FFA levels produced significant differences in glycerol levels during test 1 and test 2 , since it is well known that the Intralipid $20 \%$ emulsion contains $22.5 \mathrm{~g} / 1,000 \mathrm{~mL}$ of glycerol.

Citrate, lactate, and alanine levels were similar during the three tests. Pyruvate levels were significantly decreased during tests 1 and 2 as compared with test 3 (Table 1).

Forearm glucose uptake and metabolite balance. Forearm glucose uptake was not affected by increasing only FFA levels or both FFA and triglyceride levels as compared with the control study (Table 2). Similarly, forearm citrate and alanine release and blood flow were similar during the three tests (Table 2). In contrast, forearm $\beta$-OH-butyrate uptake was significantly greater during tests 1 and 2 versus test $3(P<.05)$.

Glucose and palmitate metabolism. Glucose turnover and hepatic glucose production were similar during the three tests (Table 3). Palmitate turnover rate was significantly greater during tests 1 and 2 versus test 3 (test 1 , $2.32 \pm 0.47$; test $2,2.48 \pm 0.33$; and test $3,1.28 \pm 0.18$ $\mu \mathrm{mol} / \mathrm{kg} \mathrm{FFM} / \mathrm{min} ; P<.05)$. No significant differences were seen between test 1 and test 2 .

Oxidative metabolism. Glucose oxidation rate was significantly lower during tests 1 and 2 versus test 3 (Table 3 ). The increase of triglyceride levels obtained during test 1 did not cause any further significant decrease in oxidative glucose disposal as compared with test 2 . Lipid oxidation rate was similar in tests 1 and 2, with values twofold greater than in test 3 (Table 3 ). Protein oxidation rate was similar during the three studies (not shown).

\section{Clamp Period}

Arterialized levels. Blood glucose was successfully clamped in all tests, with a CV of less than $5 \%$. Insulin levels achieved a plateau at $192 \pm 12,204 \pm 24$, and $234 \pm$ $12 \mathrm{pmol} / \mathrm{L}$ during tests 1,2 , and 3, respectively (NS; Fig 2).

Table 1. Blood Metabolite Levels ( $\mu \mathrm{mol} / \mathrm{L}$ ) During Control and Euglycemic, Hyperinsulinemic Clamp Periods in Six Subjects (mean $\pm \mathrm{SE}$ )

\begin{tabular}{|c|c|c|c|}
\hline Parameter & Test 1 & Test 2 & Test 3 \\
\hline \multicolumn{4}{|l|}{ Control } \\
\hline Glycerol & $373.7 \pm 57.3$ & $59.5 \pm 7.8 \dagger$ & $15.9 \pm 2.7 \ddagger$ \\
\hline$\beta$-OH-butyrate & $1,102 \pm 245$ & $434.8 \pm 60.5 \dagger$ & $55.1 \pm 11.5 \neq$ \\
\hline Citrate & $78.6 \pm 18.0$ & $92.4 \pm 17.4$ & $66.9 \pm 16.5$ \\
\hline Lactate & $561.2 \pm 46.4$ & $508.2 \pm 62.8$ & $531.8 \pm 62.8$ \\
\hline Pyruvate & $39.4 \pm 4.4$ & $34.6 \pm 4.6$ & $61.5 \pm 11.0$ \\
\hline Alanine & $246.8 \pm 26.0$ & $242.3 \pm 26.0$ & $302.3 \pm 37.9$ \\
\hline \multicolumn{4}{|l|}{ Clamp } \\
\hline Glycerol & $364.9 \pm 53.1$ & $58.1 \pm 18.6+$ & $1.1 \pm 0.4^{*} \dagger$ \\
\hline$\beta$-OH-butyrate & $1,495 \pm 461$ & $174 \pm 38^{*}+$ & $13.0 \pm 2.5^{*} \ddagger$ \\
\hline Citrate & $93.0 \pm 20.7$ & $81.3 \pm 9.9$ & $44.1 \pm 13.5 \dagger$ \\
\hline Lactate & $620 \pm 62^{*}$ & $525 \pm 60^{*}$ & $580 \pm 46^{*}$ \\
\hline Pyruvate & $47.7 \pm 6.6$ & $42.8 \pm 5.6$ & $61.2 \pm 5.3$ \\
\hline Alanine & $191.1 \pm 26.6^{*}$ & $205.0 \pm 27.6^{*}$ & $267.8 \pm 28.8^{*}$ \\
\hline
\end{tabular}

$* P<.05 v$ control period.

$+P<.05 v$ test 1

$\ddagger P<.05 v$ tests 1 and 2 .
Table 2. Forearm Glucose Uptake and Metabolite Balance During Control and Euglycemic, Hyperinsulinemic Periods in Six Subjects (mean $\pm \mathrm{SE}$ )

\begin{tabular}{llll}
\hline \multicolumn{1}{c}{ Parameter } & \multicolumn{1}{c}{ Test 1 } & \multicolumn{1}{c}{ Test 2 } & \multicolumn{1}{c}{ Test 3 } \\
\hline Control & & & \\
Glucose uptake $\dagger$ & $0.25 \pm 0.02$ & $0.47 \pm 0.11$ & $0.41 \pm 0.06$ \\
$\beta-O H$-butyrate uptake & $0.54 \pm 0.12$ & $0.31 \pm 0.03$ & $0.03 \pm 0.01 \|$ \\
Citrate release & $0.03 \pm 0.01$ & $0.02 \pm 0.00$ & $0.03 \pm 0.01$ \\
Lactate release & $0.10 \pm 0.11$ & $0.04 \pm 0.01$ & $0.21 \pm 0.13$ \\
Pyruvate uptake & $0.02 \pm 0.00$ & $0.02 \pm 0.01$ & $0.02 \pm 0.03$ \\
Alanine release & $0.12 \pm 0.02$ & $0.06 \pm 0.01$ & $0.13 \pm 0.02$ \\
FMBF* & $2.49 \pm 0.07$ & $2.51 \pm 0.10$ & $2.43 \pm 0.07$ \\
Clamp & & & \\
Glucose uptake† & $0.46 \pm 0.06 \S$ & $0.86 \pm 0.14 \pm \S$ & $1.86 \pm 0.34 \S \|$ \\
FFA uptake & $0.02 \pm 0.00$ & $0.02 \pm 0.00$ & $0.00 \pm 0.00 \|$ \\
Triglyceride uptake & $0.14 \pm 0.05$ & $0.01 \pm 0.00 \ddagger$ & $0.01 \pm 0.01 \mp$ \\
$\beta$-OH-butyrate uptake & $0.23 \pm 0.18 \S$ & $0.08 \pm 0.02 \S$ & $0.02 \pm 0.00 \ddagger$ \\
Citrate release & $0.03 \pm 0.00$ & $0.02 \pm 0.00 \ddagger$ & $0.01 \pm 0.01 \neq$ \\
Lactate release & $0.01 \pm 0.01$ & $0.10 \pm 0.05$ & $0.03 \pm 0.07$ \\
Pyruvate uptake & $0.01 \pm 0.01$ & $0.02 \pm 0.01$ & $0.01 \pm 0.01$ \\
Alanine release & $0.03 \pm 0.05 \S$ & $0.06 \pm 0.04$ & $0.13 \pm 0.02$ \\
FMBF* & $2.46 \pm 0.09$ & $2.40 \pm 0.08$ & $2.46 \pm 0.06$ \\
\hline
\end{tabular}

${ }^{*} \mathrm{~mL} / 100 \mathrm{~mL} / \mathrm{min}$

$\dagger \mu \mathrm{mol} / 100 \mathrm{~mL} / \mathrm{min}$

$\ddagger P<.05 \vee$ test 1 .

$\S P<.05 v$ control period.

$\| P<.05 v$ tests 1 and 2.

Triglyceride levels remained significantly higher during test 1 as compared with tests 2 and 3 . In contrast, FFA levels were similar between tests 1 and 2 , but significantly higher than in test 3 (Fig 2).

By the simultaneous increase of FFA and triglyceride levels (test 1), $\beta-\mathrm{OH}$-butyrate remained at levels found in the control period, with values approximately 10 - and 100 -fold those achieved during tests 2 and 3. During both tests 2 and 3, $\beta-\mathrm{OH}$-butyrate levels significantly decreased as compared with control levels, remaining significantly elevated during test 2 as compared with test 3 (Table 1 ).

During tests 1 and 2, due to the exogenous Intralipid infusion, glycerol levels were maintained at control levels (Table 1).

No significant differences were found for citrate, lactate, pyruvate, and alanine levels among the three tests (Table 1).

Forearm glucose uptake and metabolite balance. Forearm glucose uptake significantly increased during all tests as compared with each control-period level (Table 2). The

Table 3. Glucose and Oxidative Metabolism During Control Period in Six Healthy Subjects (mean \pm SE)

\begin{tabular}{lccc}
\hline \multicolumn{1}{c}{ Parameter } & Test 1 & Test 2 & Test 3 \\
\hline Glucose disposal rate† & $15.48 \pm 0.93$ & $15.24 \pm 0.97$ & $14.47 \pm 0.72$ \\
APE (90-120 min) & $2.43 \pm 0.18$ & $2.40 \pm 0.18$ & $2.48 \pm 0.11$ \\
CV of APE (\%) & $3.3 \pm 0.8$ & $4.9 \pm 1.2$ & $3.0 \pm 0.6$ \\
Hepatic glucose & & & \\
$\quad$ production & $15.48 \pm 0.93$ & $15.24 \pm 0.97$ & $14.47 \pm 0.72$ \\
Glucose oxidation $\dagger$ & $4.44 \pm 0.79$ & $5.95 \pm 0.86$ & $12.19 \pm 0.95^{*}$ \\
Lipid oxidationt & $6.23 \pm 0.38$ & $5.84 \pm 0.29$ & $3.23 \pm 0.23^{*}$ \\
\hline${ }^{*} P<.05 v$ tests 1 and 2. & & & \\
$\quad \dagger \mu \mathrm{mol} / \mathrm{kg}$ FFM/min. & & &
\end{tabular}


increase of FFA levels in the presence of normal triglyceride levels (test 2) significantly decreased forearm glucose uptake as compared with test 3 . Interestingly and at variance with the control period, the simultaneous increase of triglyceride and FFA levels (test 1) caused a significant decrease in forearm glucose uptake as compared with test 2 (Fig 3).

Forearm FFA and $\beta$-OH-butyrate uptakes were similar during tests 1 and 2, and were completely suppressed during test 3 . In contrast, forearm triglyceride uptake and forearm citrate release were significantly greater during test 1 than during tests 2 and 3 (Table 2). Blood flows were not significantly modified (Table 2).

Glucose and palmitate metabolism. Glucose turnover rate was superimposable during tests 1 and 2, but significantly lower than during test 3 (Table 4).

At high triglyceride and FFA levels (test 1), hepatic glucose production was significantly less inhibited than during tests 2 and 3 . As expected, also during test 2, hepatic glucose production was less inhibited than during test 3 (Table 4).

Once again, palmitate turnover rate was significantly greater during tests 1 and 2 versus test 3 (test 1, $2.11 \pm 0.29$; test 2, $2.09 \pm 0.35$; and test $3,0.39 \pm 0.03 \mu \mathrm{mol} / \mathrm{kg} \mathrm{FFM} /$ $\min ; P<.001)$. No significant differences were seen between test 1 and test 2 .

Oxidative metabolism. Glucose oxidation rate increased in all tests as compared with control-period levels. The increase of FFA levels (test 2) caused a significant decrease in glucose oxidation rate as compared with test 3 . By also increasing triglyceride levels (test 1), we were able to demonstrate a further significant decrease of glucose oxidation rate as compared with test 2 (Table 4).

Lipid oxidation rate was significantly greater during test 1 versus tests 2 and 3 , and during test 2 versus test 3 (Table 4). Protein oxidation rate was similar during the three studies, without significant changes as compared with the control period.

\section{DISCUSSION}

The study was designed to quantify the effects of increased triglyceride levels on glucose metabolism indepen-

Table 4. Glucose and Oxidative Metabolism During Clamp Period in Six Healthy Subjects (mean $\pm \mathrm{SE}$ )

\begin{tabular}{lccc}
\hline \multicolumn{1}{c}{ Parameter } & Test 1 & Test 2 & Test 3 \\
\hline Glucose disposal rate $^{*}$ & $19.40 \pm 1.59$ & $19.70 \pm 1.38$ & $25.31 \pm 1.66 \neq$ \\
M value* $^{*}$ & $11.39 \pm 1.09$ & $14.54 \pm 0.88 \dagger$ & $24.72 \pm 1.51 \neq$ \\
APE $(210-240 \mathrm{~min})$ & $2.62 \pm 0.15$ & $2.70 \pm 0.13$ & $2.62 \pm 0.14$ \\
CV of APE $(\%)$ & $3.5 \pm 0.9$ & $4.3 \pm 1.2$ & $3.3 \pm 0.6$ \\
Hepatic glucose & & & \\
$\quad$ production* & $8.01 \pm 1.08$ & $5.16 \pm 0.72 \dagger$ & $0.59 \pm 0.67 \neq$ \\
Glucose oxidation* & $5.08 \pm 1.21$ & $7.68 \pm 1.29 \dagger$ & $19.2 \pm 1.71 \neq$ \\
Lipid oxidation* $^{*}$ & $6.15 \pm 0.43$ & $5.20 \pm 0.22 \dagger$ & $1.26 \pm 0.31 \neq$ \\
\hline
\end{tabular}

NOTE. $M$ value is the glucose infusion rate during the last 30 minutes of the clamp.

${ }^{*} \mu \mathrm{mol} / \mathrm{kg} \mathrm{FFM} / \mathrm{min}$

$+P<.05 v$ test 1 .

$\ddagger P<.05 v$ tests 1 and 2 . dent of circulating FFA levels. For this reason, Intralipid or heparin was infused to increase both triglyceride and FFA levels in one test, and only FFA levels in the other test. Therefore, for the first time, we were able to analyze the effects of an acute increase in triglyceride levels on glucose metabolism in man. In the past, the effects of a concomitant increase in triglyceride levels by infusing Intralipid to study the effects of FFA on the Randle cycle ${ }^{29}$ were never taken into account. 12,13,30,31

In the present study, forearm glucose uptake, glucose oxidation, and hepatic glucose production were significantly decreased by $75 \%, 80 \%$, and $33 \%$ during test 1 (high triglyceride and FFA levels) and only by $54 \%, 55 \%$, and $56 \%$ during test 2 (high FFA levels). $\left[1-{ }^{13} \mathrm{C}\right]$ palmitate turnover rate was similar during tests 1 and 2, confirming that the effect of hypertriglyceridemia on glucose metabolism was independent of the circulating FFA pool. On the contrary, the findings of a higher release of citrate from muscle and higher $\beta$-OH-butyrate levels when triglyceride and FFA levels were both increased (test 1) supports the hypothesis that the intracellular fate of triglycerides and FFA was the same. In fact, we might postulate that the triglyceride hydrolysis increased the intracellular FFA pool, which in turn enhanced $\beta$-oxidation and decreased glucose utilization. Another point that validates this hypothesis was the finding of lipid oxidation being significantly increased by $15 \%$ during test 1 as compared with test 2 .

Taking our data together, we might postulate that during Intralipid infusion, at least $25 \%$ of the total decrease of forearm glucose uptake and glucose oxidation is related to hypertriglyceridemia.

The results of the present study are indirectly supported when comparing two previous experiences in which only heparin (increase in FFA levels alone ${ }^{32}$ ) or Intralipid (simultaneous increase in FFA and triglyceride levels ${ }^{13}$ ) were infused during a euglycemic, hyperinsulinemic clamp. Although FFA levels were $0.6 \mathrm{mmol} / \mathrm{L}$ in both tests, glucose oxidation was reduced by $24 \%$ in one study ${ }^{32}$ and by $35 \%$ in the other study. ${ }^{13}$ In agreement with our findings that triglyceride effects on carbohydrate metabolism are independent of the circulating FFA pool, Huttunen et $\mathrm{al}^{33}$ have demonstrated that the utilization of very-low-density lipoprotein FFA increased the intracellular but not the plasma FFA pool. On the other hand, Dagenais et al, ${ }^{34}$ Groop et al, ${ }^{32}$ and Bonadonna et al, ${ }^{35}$ using $\left[1-{ }^{14} \mathrm{C}\right]$ palmitate as a tracer of the circulating FFA pool combined with indirect calorimetry, have shown that plasma FFA accounted for $20 \%$ to $50 \%$ of total lipid oxidation in skeletal muscles. In contrast, plasma triglyceride oxidation was at least $30 \%$ of total lipid oxidation in rats. ${ }^{36}$ These data are in agreement with our findings of a $15 \%$ increase in lipid oxidation and a $25 \%$ decrease in glucose oxidation when triglyceride levels were increased in test 1 .

Another point that needs to be discussed is at which peripheral levels triglycerides can influence glucose metabolism. There is some evidence that hypertriglyceridemic NIDDM subjects (plasma triglyceride levels between 3 and $18 \mathrm{mmol} / \mathrm{L}$ ) are more insulin-resistant than NIDDM matched subjects without hypertriglyceridemia, ${ }^{6.7}$ and that 
long-term treatment with gemfibrozil improves insulin sensitivity in severely hypertriglyceridemic subjects. ${ }^{5}$ In the present study, insulin sensitivity was decreased when triglyceride levels reached $6 \mathrm{mmol} / \mathrm{L}$ in normal subjects. On the contrary, in mildly hypertriglyceridemic NIDDM subjects (plasma triglyceride levels $\sim 1.8 \mathrm{mmol} / \mathrm{L}$ ), 12 weeks of therapy with gemfibrozil decreased triglyceride levels by $42 \%$ but did not improve hemoglobin $\mathrm{A}_{1 \mathrm{C}}$ and fasting glucose levels or glucose and FFA turnover and oxidation. ${ }^{9}$ Taking all these results together, we can postulate that triglycerides play some role in glucose metabolism only when their levels are increased to $5 \mathrm{mmol} / \mathrm{L}$. Below this level, the intracellular feedback mechanism regulating FFA oxidation, recently demonstrated by Yki-Jarvinen et al, ${ }^{37}$ could also modulate triglyceride utilization. However, evaluation of the effects of incremental triglyceride levels on glucose metabolism was beyond the scope of the present study and requires further investigation.

For measuring forearm metabolite balance, we used the arterialized-deep venous difference instead of the classic arterial-deep venous difference. This method is widely accepted as a substitute for true arterial blood. ${ }^{14,31,32}$ To heat the hand, we used a warm-air box, and the arterialized oxygen saturation was between $91 \%$ and $98 \%$ (mean \pm SE,
$95.1 \% \pm 0.3 \%$ ). In addition, deep venous oxygen saturation did not significantly change before and during the heating period in all tests (before heating, $58.4 \% \pm 0.9 \%$; at the end of the control period, $56.9 \% \pm 1.8 \%$; at the end of the clamp, $61.6 \% \pm 1.9 \%$; NS). Our results confirm the study ${ }^{38}$ in which deep venous oxygen saturation remained unchanged when a correct occlusion period for the hand circulation was maintained. Different results were found by Astrup et al ${ }^{39}$ and Liu et al, ${ }^{40}$ who showed that deep venous oxygen saturation of the contralateral heated hand significantly increased by $9 \%$, but this fact is probably related to the different duration of the hand occlusion. Whereas in our study we maintained hand occlusion for 3 minutes, Astrup et $\mathrm{al}^{39}$ maintained it for 1 minute and Liu et $\mathrm{al}^{40} \mathrm{did}$ not occlude hand circulation.

In conclusion, at least under these particular conditions, acute hypertriglyceridemia induced by Intralipid infusion seems to decrease forearm glucose uptake, glucose oxidation, and insulin-induced suppressibility of hepatic glucose production. The triglyceride effect on carbohydrate metabolism seems to follow the same intracellular pathway of FFA, since triglyceride hydrolysis might increase the intracellular FFA pool without interference with the circulating FFA pool.

\section{REFERENCES}

1. Avogaro P, Crepaldi G, Enzi G, et al: Association of hyperlipidemia, diabetes mellitus and mild obesity. Acta Diabetol Lat 4:572-590, 1967

2. Reaven GM: Banting Lecture 1988. Role of insulin resistance in human disease. Diabetes 37:1595-1607, 1988

3. Olefsky JM, Farquhar JW, Reaven GM: Reappraisal of the role of insulin in hypertriglyceridemia. Am J Med 57:551-560, 1974

4. Tobey TA, Greenfield M, Kramer F, et al: Relationship between insulin resistance, insulin secretion, very low density lipoprotein kinetics, and plasma triglyceride levels in normotriglyceridemic man. Metabolism 30:165-171, 1981

5. Steiner G: Altering triglyceride concentrations changes insulinglucose relationships in hypertriglyceridemic patients. Doubleblind study with gemfibrozil with implications for atherosclerosis. Diabetes Care 14:1077-1081, 1991

6. Yki-Jarvinen H, Taskinen M-R: Interrelationships among insulin's antilipolytic and glucoregulatory effects and plasma triglycerides in nondiabetic and diabetic patients with endogenous hypertriglyceridemia. Diabetes 37:1271-1278, 1988

7. Widen E, Ekstrand A, Saloranta C, et al: Insulin resistance in type 2 (non-insulin-dependent) diabetic patients with hypertriglyceridemia. Diabetologia 35:1140, 1145, 1992

8. Shen DC, Fuh MMT, Shieh SM, et al: Effect of gemfibrozil treatment in sulfonylurea-treated patients with non insulindependent diabetes mellitus. J Clin Endocrinol Metab 73:503-510, 1991

9. Vuorinen-Markkola H, Yki-Jarvinen H, Taskinen M-R: Lowering of triglycerides by gemfibrozil affects neither the glucoregulatory nor antilipolytic effect of insulin in type 2 (non-insulindependent) diabetes patients. Diabetologia 36:161-169, 1993

10. Carlson LA, Rossner S: A methodological study of an intravenous fat tolerance test with Intralipid emulsion. Scand J Clin Lab Invest 29:271-280, 1972

11. Cowett R, Carr SR, Ogburn PL: Lipid tolerance testing in pregnancy. Diabetes Care 16:51-56, 1993

12. Ferrannini E, Barrett EJ, Bevilacqua S, et al: Effect of fatty acids on glucose production and utilization in man. J Clin Invest 72:1737-1747, 1983

13. Thiebaud D, DeFronzo RA, Jacot E, et al: Effect of long chain triglycerides infusion on glucose metabolism in man. Metabolism 31:1128-1136, 1982

14. Walker M, Fulcher GR, Sum CF, et al: Effect of glycemia and nonesterified fatty acids on forearm glucose uptake in normal humans. Am J Physiol 261:E304-E311, 1991

15. Saloranta C, Franssila-Kallunki A, Ekstrand A, et al: Modulation of hepatic glucose production by non esterified fatty acids in type 2 (non-insulin-dependent) diabetes mellitus. Diabetologia 34:409-415, 1991

16. De Fronzo RA, Tobin JD, Andres R: Glucose clamp technique: A method for quantifying insulin secretion and resistance. Am J Physiol 237:E214-E223, 1979

17. Whitney RJ: The measurement of volume changes in human limbs. J Physiol (Lond) 121:1-27, 1953

18. Cooper KE, Edholm OG, Mottram RF: The blood flow in skin and muscle of the human forearm. J Physiol (Lond) 128:258267,1955

19. Heymsfield S, McManus C, Stevens V, et al: Muscle mass: Reliable mediator of protein-energy malnutrition severity and outcome. Am J Clin Nutr 35:1192-1199, 1982

20. Finegood DT, Bergman RN, Vranic M: Estimation of endogenous glucose production during hyperinsulinemic-euglycemic glucose clamps. Comparison of unlabeled and labeled exogenous glucose infusates. Diabetes 36:914-924, 1987

21. Steele R: Influence of glucose loading and of injected insulin on hepatic glucose output. Ann NY Acad Sci 82:420-430, 1959

22. Cobelli C, Toffolo G, Bier DM, et al: Models to interpret kinetic data in stable isotope tracer studies. Am J Physiol 253:E551E564, 1987

23. Ferrannini E: The theoretical bases of indirect calorimetry: A review. Metabolism 37:287-301, 1988

24. Thorburn AW, Gumbiner B, Flynn T, et al: Substrate 
oxidation during combined indirect calorimetry-hyperinsulinemic glucose clamp studies. Metabolism 40:391-398, 1991

25. Monti LD, Sandoli PE, Costa S, et al: Fluorimetric method for the measurement of intermediate metabolites (lactate, pyruvate, alanine, $\beta$-hydroxybutyrate, glycerol) using a COBAS FARA centrifugal analyzer. J Autom Chem 15:177-181, 1993

26. Fermo I, DeVecchi E, Diomede L, et al: Serum amino acid analysis with pre-column derivatization: Comparison of the 0 phthaldialdehyde and $N, N$-diethyl-2,4-dinitro-5-fluoroaniline methods. J Chromatogr 534:23-25, 1990

27. Magni F, Monti LD, Brambilla P, et al: Determination of plasma $\left(6,6-{ }^{2} \mathrm{H}_{2}\right)$ glucose enrichment by a simple and accurate gas chromatographic-mass spectrometric method. J Chromatogr 573: 127-131, 1992

28. Magni F, Piatti PM, Monti LD, et al: Fast gas chromatographic-mass spectrometric method for the evaluation of plasma fatty acid turnover using $\left[1-{ }^{13} \mathrm{C}\right]$ palmitate. J Chromatogr 657:1-7, 1994

29. Randle PJ, Newsholme EA, Garland PB: Regulation of glucose uptake by muscle. Effect of fatty acids, ketone bodies and pyruvate, and alloxan-diabetes and starvation, on the uptake and metabolic fate of glucose in rat heart and diaphragm muscle. Biochem J 93:652-687, 1964

30. Yki-Jarvinen H, Puhakainen I, Koivisto VA: Effect of free fatty acids on glucose uptake and nonoxidative glycolysis across human forearm tissues in the basal state and during insulin stimulation. J Clin Endocrinol Metab 72:1268-1277, 1991

31. Piatti PM, Monti LD, Pacchioni M, et al: Forearm insulinand non-insulin-mediated glucose uptake and muscle metabolism in man: Role of free fatty acids and blood glucose. Metabolism 40:926-933, 1991
32. Groop L, Bonadonna R, Shank M, et al: Role of free fatty acids and insulin in determining free fatty acid and lipid oxidation in man. J Clin Invest 87:83-89, 1991

33. Huttunen JK, Ehnholm C, Nikkila EA, et al: Effect of fasting on two postheparin plasma triglyceride lipases and triglyceride removal in obese subjects. Eur J Clin Invest 5:435-445, 1975

34. Dagenais GR, Tancredi RG, Zierler KL: Free fatty acid oxidation by forearm muscle at rest, and evidence for an intramuscular lipid pool in the human forearm. J Clin Invest 58:421-431, 1976

35. Bonadonna R, Groop LC, Zych K, et al: Dose-dependent effect of insulin on plasma free fatty acid turnover and oxidation in humans. Am J Physiol 259:E736-E750, 1990

36. Wolfe RR, Durkot MJ: Role of very low density lipoproteins in the energy metabolism of the rat. J Lipid Res 26:210-217, 1985

37. Yki-Jarvinen H, Puhakainen I, Saloranta C, et al: Demonstration of a novel feedback mechanism between FFA oxidation from intracellular and intravascular sources. Am J Physiol 260:E680E689, 1991

38. Gallen IW, Macdonald IA: Effect of two methods of hand heating on body temperature, forearm blood flow, and deep venous oxygen saturation. Am J Physiol 259:E639-E643, 1990

39. Astrup A, Simonsen I, Bulow J, et al: Measurement of forearm oxygen consumption: Role of heating the contralateral hand. Am J Physiol 255:E572-E578, 1988

40. Liu D, Moberg E, Kollind M, et al: Arterial, arterialized venous, venous and capillary blood glucose measurements in normal man during hyperinsulinemic euglycemia and hypoglycemia. Diabetologia 35:287-290, 1992 